\title{
Aportaciones teóricas para la interpretación de los conflictos sociales históricos
}

Raúl Serrano

\section{Universidad Complutense de Madrid}

\section{Fecha recepción 26.10.2015/ Fecha aceptación 07.01.2016}

\section{Resumen}

El objetivo del presente artículo reside esencialmente en la presentación cronológica de los principales hitos metodológicos de carácter teórico que han sido empleados para la interpretación de los conflictos sociales en la Historia. El recorrido analítico arranca con los grandes paradigmas fundacionales de orígenes decimonónicos (darwinismo social, marxismo y estructural-funcionalismo) hasta alcanzar los enfoques más actuales.

\section{Palabras clave}

Conflictos sociales, Historia, Paradigmas, Enfoques teóricos

\section{Abstract}

The main aim of this paper is to present a chronology of the main theoretical and methodological milestones used in the interpretation of social conflicts in History. The analysis starts with the great foundational paradigms of the 19th century (social Darwinism, Marxism and structural functionalism) and finishes with the most recent advances.

\section{Key words:}

Social conflicts, History, Paradigms, Theoretical Approaches. 


\section{Introducción}

Cuando un historiador decide abordar un estudio sobre la conflictividad social de un período cronológico concreto, con unas coordenadas espaciales o geográficas definidas, y opta por dotarse de un cierto aparato teórico abstracto como mera herramienta de carácter analítico, tiene que recurrir forzosamente a la disciplina sociológica. Independientemente de la larga y compleja evolución de la práctica historiográfica, desde las concepciones rankeanas ${ }^{1}$ hasta la renovación propuesta por un proyecto de interdisciplinariedad representado en las distintas generaciones de los Annales $^{2}$ y llegando hasta las últimas tendencias ${ }^{3}$, la especialización de las Ciencias Sociales y la emancipación de la historia social han creado una situación de dependencia recíproca entre la historiografía y la teoría sociológica en el campo que nos ocupa. Ya sea desde el dogmatismo metodológico o desde el eclecticismo más pragmático, la teoría sociológica del conflicto ha inspirado en mayor o menor medida todos los trabajos históricos sobre la conflictividad social, hasta que la progresiva desconfianza y el escepticismo de la historia hacia las teorías abstractas y generalistas de la sociedad han ido bloqueando esta conexión ${ }^{4}$. A nuestro juicio, los estudios históricos sobre la conflictividad social de cualquier período no deberían encerrarse en la construcción de una narrativa factual que se desvincula por completo de la teoría, siendo la metodología analítica sin pretensiones de universalidad una solución satisfactoria, sustentada en interpretaciones pluricausales que no se alejen de las fuentes primarias de investigación.

Presentamos a continuación una síntesis organizada de las principales teorías y paradigmas sociológicos sobre el conflicto social, contemplando el eclecticismo como la vía idónea para afrontar cualquier tipo de investigación histórica en este contexto.

\section{Principales teorías y paradigmas sobre el conflicto social}

El historiador británico E. H. Carr, como manifiesto opositor del empirismo historiográfico, escribía en un célebre opúsculo que, cuanto más sociológica se haga la historia y cuanto más histórica se vuelva la sociología, mejor para ambas ${ }^{5}$. Con esta cita, el autor londinense adelantaba la necesidad teórica que exigen ciertos hechos documentados de nuestro pasado para ser correctamente interpretados. No obstante, esto no implica en absoluto una errónea adhe-

1. Recomendamos los dos volúmenes recientes de G. J. Henz, Leopold von Ranke in Geschichtsdenken und Forschung; Bd. I: Persönlichkeit, Werkenstehung, Wirkungsgeschichte. Bd. II: Grundlagen und Wege der Forschung, Berlín, 2014.

2. Vid. A. Burguière, L'École des Annales Une histoire intellectuelle, París, 2006.

3. E. Hernández Sandoica, Tendencias historiográficas actuales: escribir historia hoy, Madrid, 2004.

4. En nuestro campo específico de trabajo, la Antigüedad tardía y la historia del «Bajo Imperio romano», basta con establecer una comparativa entre los trabajos de S. I. Kovaliov, de evidente filiación teórica marxista, y los análisis más recientes, carentes ya de perspectivas teóricas que buscaban reafirmar el método a través del objeto y no al revés.

5. What is history? Harmondsworth, 1975, 66. Citado al comienzo de la obra de S. Juliá, Historia social, sociología histórica, Madrid, 1989. 
sión a viejos modelos universales de causación histórica. Se trata más bien de comprender e interpretar fenómenos, sirviéndonos de conceptos e incluso de teoría sin que el concepto ni la teoría vayan más allá de lo necesario.

En el caso concreto de los estudios sobre conflictos sociales históricos, las aportaciones teóricas siempre proceden de la disciplina sociológica, a menudo encerrada en ciertos enfoques a-históricos y especialmente presentistas. Son los sociólogos y no los historiadores, los que se han encargado de desarrollar conceptualizaciones en torno a la cuestión que se abor$\mathrm{da}^{6}$. De hecho, existe un gran número de trabajos introductorios o generalistas ${ }^{7}$ donde suelen incluirse epígrafes específicos sobre el conflicto social y donde podemos analizar la evolución de los planteamientos sociológicos dominantes al respecto.

El siglo XIX no sólo fue testigo del nacimiento de la propia sociología sino también de los intentos más acabados de búsqueda de sistemas lógico-deductivos que fueran capaces de ofrecer una explicación al fenómeno de la conflictividad social. Hablamos del darwinismo social y sobre todo del marxismo. Los darwinistas sociales ${ }^{8}$, en contra de las consideraciones del mismo Darwin, defendieron que la teoría de la evolución podía aplicarse a las sociedades e instituciones humanas. En este sentido, interpretaron que el conflicto social era consustancial a cualquier sociedad, en un contexto de supervivencia del más apto. Bien es cierto que su ineficacia argumentativa ya fue pertinentemente denunciada por autores como S. J. Gould 9 .

Por su parte, el marxismo ${ }^{10}$ se encargó de buscar las causas del conflicto en la misma estructura social y de emplear el propio concepto como factor explicativo del cambio histórico. Ambos planteamientos coinciden en un punto, puesto que el darwinismo social colabora al apuntalamiento del statu quo y el marxismo a su disolución en nombre del proletariado. Sin embargo, la teoría sociológica marxista no aprecia el conflicto como una confrontación justificada e inevitable en la lucha por la existencia, sino que contempla una división social entre poseedores y no poseedores de los recursos y de los medios de producción, como raíz de la aparición de las clases sociales, basadas a su vez en la posición que ocupan los individuos en la estructura de las relaciones de producción. Así pues, la dialéctica como concepción de que la realidad está en constante movimiento y es esencialmente contradictoria se convierte en el

6. J. Del Pino Artacho, por poner un ejemplo, define el conflicto social como un proceso que nace de la contraposición de intereses y valores en una sociedad, en un capítulo ad hoc de un manual de sociología. "Conflicto social” en S. Del Campo, (Ed.), Tratado de Sociología, 2, Madrid, 1991, 267 ss.

7. Vid. G. Rocher, Introducción a la sociología general, Barcelona, 1990, 491 ss; A. I. Blanco García, "El conflicto social” en A. Hernández Sánchez, (Coord.), Manual de sociología, Valladolid, 1998, 115-129, entre muchos otros.

8. Vid. M. Hawkins, Social darwinism in European and American thought, 1860-1945: nature as model and nature as threat, Cambridge, 1997. Para profundizar en los textos originales de los darwinistas sociales, $\mathrm{H}$. Spencer, Los primeros principios, Granada, 2009;

9. La falsa medida del hombre, Barcelona, 2007. Este gran divulgador científico estadounidense rechazó la sociobiología como ámbito académico aplicado al estudio de los seres humanos.

10. G. Therborn, Del Marxismo al postmarxismo, Madrid, 2014; R. Aron, El marxismo de Marx, Madrid, 2010; K. Marx, El Capital: crítica de la economía política. Libros I, II, III con sus tres tomos correspondientes para cada libro, Madrid, 2012. 
fundamento de cualquier conflicto manifiesto ${ }^{11}$. Las pretensiones científicas y predictivas que asocian la conflictividad social en su conjunto con una lucha de clases omnipresente, dual y antitética, atentan contra la experiencia histórica. Aun así, cualquier estudio sobre conflictos sociales históricos ha de seguir considerándose un deudor del pensamiento marxista.

Georg Simmel ${ }^{12}$ es un autor crucial en la evolución de las teorías interpretativas del conflicto social, en tanto en cuanto puede ser considerado como el puente entre la teoría del conflicto marxista y el funcionalismo crítico posterior. Para este autor, el conflicto actúa en contra de la cohesión de la sociedad, pero es un hecho universal que puede tener consecuencias positivas para el colectivo, fortaleciendo sus vínculos a posteriori. Dicho de otro modo, e inspirando profundamente el pensamiento de L. A. Coser ${ }^{13}$, el conflicto social no es solamente un elemento disfuncional, sino también funcional.

El funcionalismo estructural hunde sus raíces de igual modo en el período decimonónico ${ }^{14}$, pero su consolidación se corresponde con las primeras décadas del pasado siglo XX. El conflicto sería apreciado por este paradigma teórico como una desviación patológica de algunos elementos de la estructura, algo periférico y advenedizo que se contrapone al estado normal de la sociedad. Partiendo de la convicción de que una sociedad es un conjunto integrado, funcional y coherente, E. Mayo ${ }^{15}$ vinculaba los conflictos sociales con situaciones individuales de inadaptación a una estructura funcional. R. K. Merton ${ }^{16}$, todo un clásico de la escuela sociológica estadounidense, sí apreció la posibilidad de que el conflicto tuviera un origen estructural pero siempre lo consideró disfuncional. En la misma dirección incluimos a T. Parsons ${ }^{17}$, otro eminente sociólogo estructural-funcionalista estadounidense, poco o nada

11. «El conflicto es la forma en que se manifiestan históricamente las contradicciones entre las fuerzas materiales de producción y las relaciones de producción». Con esta cita de Marx en B. Tejerina Montaña, "Las teorías sociológicas del conflicto social. Algunas dimensiones analíticas a partir de K. Marx y G. Simmel", Reis, Revista española de investigación sociológica, 55, 1991, 47-63, se corrobora lo expuesto.

12. Destacamos para nuestro estudio dos trabajos del filósofo y sociólogo alemán. El conflicto: sociología del antagonismo, Madrid, 2010; Sociología: estudios sobre las formas de socialización, Madrid, 1986.

13. Sobre este sociólogo alemán emigrado a los Estados Unidos, hablaremos en profundidad a lo largo de nuestro trabajo.

14. No podemos obviar los trabajos antropológicos de B. Malinowski, como antecedentes directos de la escuela funcionalista. Al respecto, Vid. O. Fernández Álvarez, Bronislaw Malinowski: la antropología y el funcionalismo, León, 2004. Para profundizar en el autor, Vid. M. W. Young, Malinowski: odyssey of an anthropologist, 1884-1920, New Haven, 2004. Asimismo, la teoría social funcionalista está directamente asociada con el pensamiento de É. Durkheim. El compendio de A. Giddens, Escritos selectos/ Émile Durkheim, Buenos Aires, 1993, puede ser de gran utilidad para una primera aproximación al sociólogo francés.

15. Este teórico social negaba que el conflicto fuera un problema estructural. Sus trabajos más importantes en relación con la teoría de las organizaciones y las relaciones humanas podrían ser: The human problems of an industrial civilization, New York, 2004; The social problems of an industrial civilization, London, 1952.

16. Vid. Teoría y estructuras sociales, México, 2002.

17. Vid. S. P. Savage, The theories of Talcott Parsons: the social relations of action, London, 1983; J. Almaraz, La teoría sociológica de Talcott Parsons: la problemática de la constitución metodológica del objeto, Madrid, 1981. 
interesado en el cambio social y en los conflictos asociados e imbuido de una óptica conservadora de la sociedad.

La última corriente teórica de inicios del siglo XX que acabó por ofrecer una nueva interpretación de los conflictos sociales fue la teoría de juegos ${ }^{18}$. Procedente de la matemática aplicada, comenzó a adoptar formas sólidas de independencia metodológica con los artículos de J. von Neumann aunque hasta los años 50 no surgieron las primeras aplicaciones en filosofía y ciencia política. A mediados del siglo XX, se produce de hecho un cambio de paradigma teórico con respecto a los estudios interpretativos sobre la conflictividad social, caracterizado por la superación de las tesis más tradicionales del estructural-funcionalismo y del marxismo pero sin perder de vista sus grandes aportaciones originarias.

\section{El nuevo paradigma: L. A. Coser y R. Dahrendorf}

Independientemente de los antecedentes teóricos expuestos, el propio L. A. Coser ${ }^{19}$ era muy consciente de que la conflictividad social no era todavía un campo de estudios suficientemente explorado y reclamaba una renovación de la sociología del conflicto puesto que, a su juicio, desde Simmel había permanecido estática como consecuencia del inmovilismo del estructural-funcionalismo norteamericano. La percepción imperante del conflicto como elemento destructivo, desintegrador y anti-funcional sostenida por la gran mayoría de los sociólogos estadounidenses en plena Guerra Fría ${ }^{20}$ llevó a Coser a reconsiderarlo como una parte posiblemente necesaria y positiva de todas las relaciones sociales. Así pues, retomando las ideas de Simmel, Coser comienza a reivindicar la funcionalidad del conflicto social ${ }^{21}$.

Acertadamente, este autor advierte que las simples actitudes de hostilidad y antagonismo pueden cristalizar o no en conflicto. Mientras que el conflicto modifica los términos de la interacción, la simple expresión de los sentimientos hostiles no lo hace ${ }^{22}$. Por su parte, distingue entre conflictos reales o motivados por un objetivo concreto y conflictos irreales, donde el fin es la mera liberación de agresividad. A su vez, la energía afectiva o el odio al antagonista

18. Un texto introductorio podría ser K. G. Binmore, La teoría de juegos: una breve introducción, Madrid, 2009. En 1944, J. von Neumann publica junto con O. Morgenstern, Theory of Games and Economic Behavior. Otros avances en el desarrollo de la teoría de juegos antes de su aplicación a las ciencias sociales fueron el "dilema del prisionero" planteado por A. W. Tucker, o el equilibrio de J. F. Nash, Vid. W. Poundstone, El dilema del prisionero: John von Neumann, la teoría de juegos y la bomba, Madrid, 2012; E. V. Damme, Stability and perfection of Nash equilibria, Berlín, 1996.

19. En 1956, L. A. Coser publicaba The functions of social conflict, traducida al castellano pocos años después. Vid. Las funciones del conflicto social, México, 1961.

20. Ibid., 27. En los pasajes iniciales del trabajo, Coser critica las connotaciones políticas que llevan a los sociólogos a tratar de evitar el conflicto social, cuando su auténtica labor debería ser la producción científica independiente. En este mismo contexto señala las obras de C. H. Cooley., T. Parsons, G. A. Lundberg, E. Mayo, o L. Warner.

21. Coser afirma que a través del conflicto, las identidades de los grupos se crean y se fortalecen, ya sean conflictos de clases, etnias o naciones.

22. Ibid., 49. 
unido a la motivación real de la lucha, robustecen las partes en conflicto. Sin duda el componente afectivo, más habitual en los grupos cohesionados, recrudece los conflictos ${ }^{23}$. Parece evidente que los conflictos externos fortalecen al grupo y que el enemigo interno representa la mayor amenaza para la unidad del mismo. Coser detecta los conflictos que afectan a los principios fundamentales del sistema de cohesión social y a las bases del consenso como los más peligrosos ${ }^{24}$. Por tanto, aprecia la flexibilidad como una herramienta óptima para resistir las tensiones sin rupturas. Para concluir, se destaca la diferencia entre las metas personales o impersonales como factor de análisis en la conflictividad social, siendo éstas últimas más susceptibles de generar comportamientos más radicales como consecuencia del componente trascendental. La abstracción de un conflicto lo radicaliza y los casos más destructivos de conflicto se producen cuando los antagonistas comparten metas de carácter supraindividual $^{25}$. La síntesis que se aborda en los dos capítulos que cierran Las funciones del conflicto social $^{26}$, reincide en sus consecuencias positivas, como por ejemplo el nacimiento de nuevas leyes o la vuelta a una estabilidad más consolidada después de la confrontación.

Por su parte, en 1957 Ralf Dahrendorf se presenta como uno de los autores más influyentes en la renovación de la teoría del conflicto social a través de su famosa obra Soziale Klassen und Klassenkonflikt in der industriellen Gesellschaft ${ }^{27}$. Como crítico del funcionalismo norteamericano y gran conocedor de la obra de Marx, este sociólogo de Hamburgo nacido en el período de entreguerras, se encargó de matizar en muchos aspectos y actualizar en buena medida algunos conceptos clave en la teoría social marxista ${ }^{28}$. En primer lugar, cuestionó el dualismo de clases y la identificación absoluta entre propiedad y dominio, poder económico

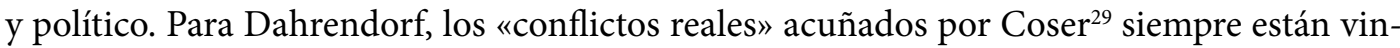
culados a la conciencia de clase, puesto que toda sociedad humana ha conocido y conoce la distribución dicotómica del poder y de la autoridad pero esto no implica que todos los con-

23. En relación con el componente afectivo en los conflictos sociales, la ambivalencia freudiana (del amor al odio sólo hay un paso) explicaría los tan habituales conflictos internos de grupo.

24. L. A. Coser, op. cit., n. 15, 84.

25. Ibid., 136.

26. Capítulo VII, "Conflicto unificador”, 136 ss, y capítulo VIII, 158 ss, "Conflicto reclama formación de alianzas". En este último se define el concepto de cooperación antagonística, consistente en la alianza de dos grupos frente a un enemigo común que puede desembocar en una fusión o bien integrar una mera coalición temporal.

27. Recomendamos la siguiente traducción al castellano: R. Dahrendorf., Las clases sociales y su conflicto en la sociedad industrial, Madrid, 1974.

28. Con respecto al concepto de clase social, Dahrendorf afirma que «el término ha tenido una historia tan agitada como la propia sociedad para la que ha sido desarrollado». Ibid., 19. Partiendo de la premisa de que Marx no llegó a desarrollar en su plenitud la teoría de las clases sociales en el inconcluso III volumen de El Capital, el autor considera que las tesis marxistas nunca pretendieron ofrecer una rigurosa descripción fotográfica de las sociedades del presente ni de las sociedades históricas del pasado; Marx tan sólo trató de elaborar un prototipo explicativo que nos ayudara a interpretar el modo en el que una sociedad modifica su morfología estructural.

29. Cf. Supra, 4. 
flictos existentes sean o hayan sido «conflictos de clase» ${ }^{30}$. Asimismo, cuestiona la dinámica histórica marxista sustentada en una teoría del cambio estructural originado mediante revoluciones, alegando que el mesianismo del proletariado y de la sociedad definitiva sin clases no tiene correspondencia empírica alguna. No obstante, reconoce que una vez liberada de todo el lastre especulativo, la teoría marxista de las clases contiene aún abundantes ideas y elementos que ni deben ni pueden dejar de ser tomados en consideración ${ }^{31}$. El análisis principal de esta obra se focaliza mediante una adaptación sustancial de la teoría del conflicto de raigambre marxista a las sociedades industriales desarrolladas y occidentales de la posguerra europea ${ }^{32}$. En dicho estudio, se acentúan las pertinentes diferencias entre propiedad y control de los medios de producción, se pone en entredicho la supuesta evolución del proletariado hacia una total homogeneidad y se hace especial hincapié en los procesos de ascenso y descenso social en apreciable aumento en los últimos períodos considerados, no contemplados por Marx. Concluyendo, Dahrendorf esboza la idea de un futuro de sociedades de clases sin lucha de clases $^{33}$, regresando a un orden jerárquico de sectores o estratos. En cualquier caso, para hablar con exactitud de lucha de clases, resulta imprescindible la existencia de grupos de interés organizados con objetivos manifiestos en oposición ${ }^{34}$. Por el contrario, los cuasigrupos con un menor grado de organización y sin objetivos manifiestos pueden protagonizar un conflicto social, causado por la tenencia o carencia de poder y autoridad, pero en ningún caso será éste un «conflicto de clase».

Asentando el nuevo paradigma y superando las corrientes teóricas que les precedían, tanto Coser $^{35}$ como Dahrendorf ${ }^{36}$ publicarán nuevos trabajos de apreciable trascendencia académica en la década de los 60 y 70. Desde el funcionalismo crítico, Coser se mantiene más reticente a brindar reconocimientos a Marx, a diferencia de Dahrendorf, pero continúa considerando necesario el conflicto porque dinamiza y revitaliza las sociedades. A su modo de ver, la rigidez de un sistema social intensifica los conflictos mientras que la flexibilidad los aminora $^{37}$. Una sociedad bien integrada tolerará e incluso recibirá con agrado el conflicto de grupo, sólo han de temer el conflicto aquellas sociedades que estén débilmente integradas ${ }^{38}$.

30. R. Dahrendorf, op. cit., n. 23, 44.

31. Ibid., 52.

32. Nos referimos, obviamente, al período inmediatamente posterior a la Posguerra de la Segunda Guerra Mundial.

33. Como consecuencia de los progresos democráticos de las naciones capitalistas que habrían reducido drásticamente la desigualdad a través del "aburguesamiento" de los sectores trabajadores y de la nivelación social. La democracia política aspira a crear normas para regular el conflicto, usando como herramienta principal la institucionalización del antagonismo de clases. R. Dahrendorf, op.cit., n. 23, 101.

34. Ibid., 229.

35. L. A. Coser, Nuevos aportes a la teoría del conflicto social, Buenos Aires, 1970. El texto original, Continuities in the Study of Social Conflict, fue publicado en 1967.

36. R. Dahrendorf, Oportunidades vitales: notas para una teoría social y política, Madrid, 1983. La primera edición alemana se retrotrae al año 1979: Lebenschancen. Anläufe zur sozialen und politischen Theorie.

37. Cf. Supra, 4.

38. R. Dahrendorf, op. cit., n. 32., 40. 
Asimismo, apunta que la privación relativa de status, riqueza y autoridad, que abriga esperanzas de progresión social se muestra más potencialmente revolucionaria que la privación absoluta $^{39}$, más característica de sociedades de estratos en etapas preindustriales. Algunas categorías de individuos están ubicados de tal modo en la estructura social que se ven excluidos del acceso legítimo a la escalera de logros; cuando esos canales están obstruidos, la violencia puede ofrecer vías alternativas para el $\log \mathrm{o}^{40}$.

A su vez, Dahrendorf desarrolla el concepto de «oportunidades vitales» como punto de arranque para entender los orígenes de los conflictos sociales ${ }^{41}$. En términos casi matemáticos, nos presenta la equivalencia de las oportunidades vitales como la suma entre opciones y ligaduras $(\mathrm{O} . \mathrm{V}=\mathrm{L}+\mathrm{O})$. Independientemente del peso que puedan tener ambos elementos y de cómo puede decantarse la balanza de las oportunidades vitales para los diversos sectores de la sociedad, en función de las cantidades representadas por las opciones y las ligaduras, el autor siguió apreciando el conflicto como un mecanismo de progreso.

\section{Otras contribuciones más recientes}

El economista estadounidense Thomas C. Schelling ${ }^{42}$ publicaba en 1960 uno de los trabajos más influyentes de las últimas décadas en relación a la teoría del conflicto ${ }^{43}$. Su concepto de estrategia asociado a la idea de conflicto permanente se adhiere a la vanguardia metodológica de los trabajos pioneros de Coser y Dahrendorf, pero en su caso, el foco de atención recae sobre los participantes en disputa, mientras que la perspectiva teórica procede de la teoría de juegos ${ }^{44}$. En un desarrollado programa clasificatorio, define los «conflictos puros» como la contraposición total de intereses de los antagonistas ${ }^{45}$. Empero, Schelling considera que este tipo de confrontación representa un caso extraordinario en su presente, existiendo siempre la posibilidad de la negociación y de la acomodación mutua para evitar la destrucción

39. Ibid., 70 .

40. En relación a las «funciones señalizadoras» de la violencia, Coser estaría exponiendo una explicación visible a las permanentes manifestaciones violentas del conflicto social en las sociedades que carecen de mecanismos de institucionalización. Ibid, 77.

41. Los conflictos sociales versan sobre la posibilidad de conseguir más oportunidades vitales y sobre la posibilidad de defender los niveles alcanzados. Los grupos dominantes, considera Dahrendorf, tratan de asegurar las opciones convertidas en privilegio en el marco de unos vínculos o ligaduras imperantes. Según el criterio de los grupos dominados, el anhelo reside en obtener la implantación de nuevas opciones $\mathrm{y}$ acabar con las ligaduras vigentes.

42. Schelling ha diversificado sus estudios abordando materias tales como la estrategia militar y el control de armas, la política energética y medioambiental, el cambio climático, el terrorismo o la segregación e integración racial. No obstante, sus avances en la teoría del conflicto y en la negociación le acreditaron como Nobel de Economía en 2005 junto con R. J. Aumann.

43. T. C. Schelling, The strategy of conflict, Cambridge-Massachusetts, 1960.

44. Cf. Supra, 3.

45. T. C. Shelling, op. cit., 4. 
recíproca ${ }^{46}$. Así pues, y haciendo uso de la terminología característica de la teoría de juegos, la gran mayoría de los conflictos sociales coetáneos se podrían interpretar como juegos de suma variable ${ }^{47}$ o potenciales situaciones de negociación. La negociación en el conflicto puede emplear una gran diversidad de estrategias, incluyendo la amenaza y la disuasión, el compromiso o las promesas. Todos estos movimientos pertenecen a la estrategia con la que afrontamos un conflicto.

En 1965, otro destacado economista y sociólogo estadounidense protagonizó importantes contribuciones para la interpretación teórica de la formación organizada de grupos sociales que persiguen un mismo fin y que pueden desencadenar un conflicto. En The Logic of Collective Action: Public Goods and the Theory of Groups, M. Olson ${ }^{48}$ afirma, desde postulados marcadamente neoliberales, que los individuos se agrupan para obtener beneficios. Cuanto mayores sean los beneficios que pueden alcanzar, mayor será la implicación de los individuos en el grupo. Por tanto, el incentivo sería un elemento crucial para el mantenimiento de un grupo organizado, así como la coacción, partiendo de unas nociones profundamente egoístas sobre la naturaleza individual. Para Olson, la lucha de clases es una lucha egoísta basada en perspectivas consistentes en mejorar situaciones individuales ${ }^{49}$.

En los años 70, la sociología norteamericana seguirá protagonizando los desarrollos teóricos más importantes en este campo académico, de la mano de L. Kriesberg ${ }^{50} \mathrm{o}$ R. Collins ${ }^{51}$.

Pese a sus raíces funcionalistas, Kriesberg identifica los conflictos sociales como algo inherente a las relaciones humanas ${ }^{52}$, si bien se muestra especialmente interesado en advertir las diferencias tipológicas de los mismos. En su opinión, cualquier estudio analítico de un conflicto social histórico o contemporáneo tiene que abordar sus características particulares $^{53}$. La autoconciencia de grupo como entidad colectiva, por oposición a otro grupo, se for-

46. El contexto histórico y geopolítico del período de la Guerra Fría determina muy visiblemente los postulados de la obra mencionada.

47. Según la teoría de juegos, un juego de suma cero no cooperativo describe un conflicto en el que la ganancia o la pérdida de una de las partes equivale a las pérdidas o ganancias del antagonista. Es decir, si por ejemplo la ganancia de una parte (5) se resta a las pérdidas del antagonista (ha de ser exactamente la misma cantidad, 5) se obtiene siempre 0 como resultado; hablamos de conflictos puros. Por el contrario, los juegos de suma variable o no nula se caracterizan por el esquema ganancia-ganancia mediante la negociación en lugar de ganancia-pérdida. Vid. R. Leonard, Von Neumann, Morgenstern, and the creation of game theory: from chess to social science (1900-1960), N. York, 2010.

48. M. Olson, La lógica de la acción colectiva: bienes públicos y la Teoría de grupos, México, 1992.

49. M. Olson, op. cit., 118.

50. Vid. L. Kriesberg, Sociología de los conflictos sociales, México, 1975.

51. Vid. R. Collins, Conflict Sociology: Toward an Explanatory Science, N. York, 1975.

52. L. Kriesberg, op. cit., 13.

53. Vid. el grado de intensidad, que depende de los medios empleados por cada una de las partes para alcanzar sus objetivos; también recomienda el estudio de las categorías sociales que configuran cada una de las unidades conflictivas. Los conflictos por disentimiento consisten en la existencia incompatible de metas muy diversas, mientras que los conflictos de base consensual representan la confrontación entre dos partes que aspiran a alcanzar el mismo objetivo. Ibid, 52. Destaca igualmente la interdependencia entre la 
ma y transforma precisamente en el curso de un conflicto; un grupo insatisfecho cree que si sus exigencias sobre otro grupo se satisfacen, su descontento disminuirá ${ }^{54}$. La insatisfacción, sin embargo, no siempre desencadena una conducta conflictiva puesto que el descontento ha de ser muy intenso, estar compartido por un número significativo de personas y encauzarse a la persecución de algún fin al que se oponga otro sector social ${ }^{55}$. Difícilmente podemos detectar un conflicto social sin incompatibilidad de metas u objetivos, y que a su vez mantengan un cierto equilibrio con respecto a los esfuerzos utilizados para alcanzar dichos logros. Asimismo, en este gran trabajo analítico, Kriesberg contempla la existencia de líderes como un factor esencial en los conflictos, capaz de incrementar los sentimientos de descontento a través de la proyección de un futuro mejor para el colectivo determinado ${ }^{56}$. Propone además la medición sustancial del tamaño de las partes en conflicto, de la fracción de poder de la que disponen y de las expectativas con las que cuentan para obtener sus anhelos, con la intención de interpretar con mayor precisión la confrontación. Aconseja igualmente el estudio de las ideologías que subyacen en las unidades conflictivas, los recursos empleados, los medios escogidos para dirigirse a las metas o la capacidad de reacción de los adversarios ${ }^{57}$.

En esta misma línea, marcada por el pragmatismo metodológico y la fenomenología social como respuesta, Collins ${ }^{58}$ aboga por los análisis comparativos y las variaciones, tratando de evitar los excesos de las abstracciones propias de la hipostatización teórica y de los reduccionismos extremos procedentes de la micro-sociología.

Contrario al funcionalismo y al marxismo, por la motivación plenamente ideológica que dinamiza ambas corrientes, considera muy necesario un desarrollo científico de la teoría sociológica del conflicto alejado de este tipo de prejuiciosos condicionantes. Collins es partidario de escoger conceptos propios en el proceso de una explicación óptima, mucho más allá de resonancias evaluativas ${ }^{59}$. Además, manifiesta sus hondas preocupaciones históricas promoviendo un trabajo interdisciplinar que ofrezca soluciones causales a las grandes incógnitas sobre la conflictividad social del pasado y del presente ${ }^{60}$. El sociólogo de Tennessee trata

consciencia del conflicto, la satisfacción o insatisfacción que mueve a las partes a entrar en el conflicto y las metas propuestas por éstas.

54. Ibid., 84. Kriesberg afirma que la insatisfacción social como móvil de un conflicto se corresponde con las privaciones. Los estratos inferiores suelen ser los más insatisfechos, como consecuencia del desequilibrio de posiciones. No obstante, hay veces que los grupos emergentes y ascendentes son más conscientes de sus posibilidades y a menudo su ambición incrementa su insatisfacción.

55. Ibid., 104.

56. Ibid., 111.

57. El trabajo de L. Kriesberg reflexiona también sobre otros aspectos destacables como los «terceros» o aliados posibles de los grupos en conflicto, tácticas desplegadas durante la lucha, escalamientodesescalamiento y resultados finales.

58. Randall Collins es conocido por sus esfuerzos académicos orientados hacia la hibridación de enfoques macro-sociológicos y micro-sociológicos con una perspectiva histórica.

59. R. Collins, op. cit., 23.

60. «La historia debería verse también como un campo en el cual los principios generales encuentran su aplicación y, así pues, sería un lugar para comprobar y desarrollar teorías sociológicas». Ibid., 36. 
de profundizar su análisis concreto sobre los conflictos sociales a través de un estudio progresivo sobre la estratificación, reconociendo los méritos de las explicaciones pluricausales de Max Weber ${ }^{61}$. Convencido de la importancia de los modelos fenomenológicos basados en las interacciones sociales de los individuos, atiende a las variables de la estratificación ${ }^{62}$ desde ciertos horizontes subjetivos, destacando el concepto de los «recursos conversacionales» ${ }^{63}$. Collins concluye la obra en cuestión ampliando la tipología del conflicto social, extendiendo sus estudios a la estratificación sexual y a la desigualdad generada por las diferencias de edad, riqueza, poder y prestigio.

Para inicios de la década posterior, destacamos las aportaciones de John Rex y Julien Freund. El primero, británico nacido en Sudáfrica, contempló el análisis de los conflictos como una cuestión esencialmente útil no sólo para la teoría sociológica sino para cualquier tipo de sociedad. Procedente de la escuela anglosajona y más reacio al funcionalismo que al marxismo, publicó en 1981 Social Conflict: A Theoretical and Conceptual Analysis ${ }^{64}$. En este trabajo, haciendo uso de una terminología con reminiscencias psicológicas ${ }^{65}$, Rex sintetiza los conflictos como una contraposición de expectativas y de sanciones. Con una influencia notoria de Simmel y Coser, considera que las sociedades más abiertas poseen cauces e instituciones capaces de evitar el estallido violento del conflicto, que concluye a su vez cuando una de las partes impone a la otra sus definiciones morales o cognoscitivas de la situación ${ }^{66}$. Para el autor, el ejercicio de la violencia física es la alternativa a un orden normativo, pero cuando éste impera de manera oportuna, dicha estrategia se convierte en la sanción última en una escala de drasticidad de los medios empleados en el conflicto. En tales circunstancias, las bases fundamentales de la ley y el orden se habrán quebrantado y aunque a pequeña escala, se producirá un estado de guerra civil ${ }^{67}$. Adoptando de igual

61. Ibid. 49. Max Weber fue el artífice principal de la asociación teórica entre Estado y monopolio institucional de la violencia mediante las estructuras burocráticas. La clasificación weberiana de las clases económicas, más compleja que la marxista, influyó enormemente en el pensamiento de autores como Dahrendorf o el propio Collins. Vid. M. Weber, Economía y sociedad, México, 2014; M. Weber, (1864-1920):

La ciencia como profesión; la política como profesión, Madrid, 2001.

62. Ibid., 62 ss. Se refiere a la ocupación profesional, a las relaciones de dominio y a la posición obtenida en el sistema de ofrecimientos-mandatos o recepciones de órdenes.

63. En este punto, Collins se muestra como un seguidor de las teorías de E. Goffman, Frame Analysis: los marcos de la experiencia, Madrid, 2006. Erving Goffman (1922-1982) es considerado hoy como el padre de la micro-sociología. Este autor canadiense, observó el análisis sobre cualquier fenómeno histórico como un ejercicio que involucra a nuestros marcos de referencia primarios. Los marcos primarios responden a una serie de claves morales cambiantes. Así pues, las cuestiones que versan sobre acontecimientos que ocurrieron en un pasado lejano son especialmente vulnerables, pues parece obviamente cierto que cuanto más atrás en el tiempo tuvieron lugar, más difícil resulta recoger evidencias disponibles y más confianza hay que depositar en cualquier registro que pueda ser rastreado, 467.

64. Recomendamos la siguiente traducción al castellano: J. Rex, El conflicto social: un análisis conceptual y teórico, Madrid, 1985.

65. Nos referimos al empleo constante de Ego/Alter.

66. Ibid., 16.

67. Ibid., 22. 
modo concepciones originarias de Schelling ${ }^{68}$ y de la teoría de juegos, interpreta la lucha de clases como un proceso de negociación.

Julien Freund ${ }^{69}$, por el contrario, se muestra mucho más beligerante con el marxismo en Sociologie du Conflit ${ }^{70}$. Siendo muy consciente de que todas las sociedades del pasado han sido sacudidas de forma intermitente por luchas cuya intensidad era en ocasiones considerable, afirma que el conflicto social es de orden vivencial, inmediato o repetido en el tiempo, con períodos de calma y de erupción ${ }^{71}$. Más allá de asegurar que el conflicto es inherente a toda sociedad, Freund se asienta en la improbabilidad de la supresión definitiva de los mismos. Próximo a las nociones aristotélicas de la sociedad natural, aprecia también el conflicto como un acontecimiento natural que nunca podrá ser erradicado completamente. Tanto el liberalismo como el socialismo han desarrollado a su juicio una falsa idea de progreso, sustentada en la fe sobre la aniquilación de los conflictos. Por esta razón, el autor opta por consolidar una auténtica disciplina académica ${ }^{72}$ que se encargue de estudiar los conflictos humanos como factor omnipresente en la historia pasada, presente y futura de nuestra especie. Establece además una tipología de los conflictos, consistente en la distinción entre lucha y combate. ${ }^{73}$ En este punto, el objetivo social sería la conversión de las luchas en "competiciones» o combates no violentos plenamente reglamentados, retomando la antigua teoría de Coser sobre la institucionalización del antagonismo ${ }^{74}$ como mecanismo para minimizar conflictos. Con respecto a la relación causal, no sería homogénea, pues los conflictos pueden estar originados por causas que no son del mismo orden y que pueden estar entremezcladas con razones sociales, psicológicas, políticas, religiosas u otras ${ }^{75}$. Frente a explicaciones acientíficas y mono-causales, insiste en el pluralismo y el particularismo de los conflictos sociales.

Freund concluye su estudio profundizando en el análisis sobre los conflictos engendrados por una situación concreta o sobre aquellos que se superponen mediante la premeditación. La escalada hacia el conflicto, desde la tensión como síntoma habitual del estado agonal,

68. Cf. Supra, 7.

69. Este sociólogo francés, de pensamiento liberal-conservador muy crítico, cuenta con una abundante producción científica escrita tanto en francés como en alemán.

70. Recomendamos la siguiente traducción al castellano: J. Freund, Sociología del conflicto, Madrid, 1995.

71. Ibid., 21.

72. La "polemología", en sentido amplio, sería la citada disciplina encargada de abordar el estudio de los conflictos humanos con un objetivo evidente orientado a la resolución o a la prevención de éstos. El neologismo fue acuñado por G. Bouthoul (Vid.Traité de Polémologie: sociologie des guerres: MéthodesDoctrines et Opinions sur la guerre, París, 1970) pero el propio Freund fundó el Instituto de Polemología en Estrasburgo.

73. Ibid., $62 \mathrm{ss;} \mathrm{La} \mathrm{lucha} \mathrm{sería} \mathrm{una} \mathrm{forma} \mathrm{indeterminada} \mathrm{de} \mathrm{conflicto} \mathrm{sin} \mathrm{objetivo} \mathrm{aparente,} \mathrm{donde} \mathrm{el}$ enemigo no está visibilizado (tumultos, motines, depredaciones...), obra de la penuria mayoritariamente. Las luchas suelen desaparecer por agotamiento momentáneo, pero cuando se dotan de promotores con ascendiente sobre el colectivo, capaces de imponer una relativa organización, se convierte en un combate.

74. Cf. Supra, 4-6.

75. Ibid., 107. 
sería junto a la descripción del terreno, la intensidad cambiante o las tácticas empleadas, uno de los últimos epígrafes tratados en cuestión.

Mucho más próximo al marxismo, aunque abierto partidario del individualismo metodológico, el noruego Jon Elster ${ }^{76}$ cuestionaba en 1984 todas las grandes corrientes explicativas centradas en colectivos y macro-conceptos. Desde su punto de vista, el paradigma más adecuado para las ciencias sociales ha de basarse en explicaciones mixtas, con una combinación de perspectivas macro y micro, que no olviden que los «conflictos sociales» son abstracciones teóricas que ensombrecen la realidad experimentada por los individuos que están auténticamente involucrados. Elster asegura que la teoría de juegos podría combinarse con el análisis social marxista sin abandonar la atención hacia el individuo. Asimismo, reconoce algunas aportaciones apreciables en la obra de Olson ${ }^{77}$, pero introduce la posibilidad de la «lógica racional de la cooperación» en los grupos, frente a la lógica de la acción colectiva fundamentada en el egoísmo individualista.

La dificultad para innovar en el campo de la teoría sociológica del conflicto se pondrá de manifiesto en los años 90, década en la que tan sólo podríamos destacar alguna necesaria aportación de sistematización y revisión de lo establecido ${ }^{78}$. En esta dirección, Benjamín Tejerina Montaña expone críticamente en un artículo los principios fundamentales de la teoría marxista del conflicto y los compara con las ideas de Simmel al respecto, proponiendo analizar los conflictos sociales prestando atención tanto a los elementos materiales como a las representaciones mentales que las partes implicadas reproducen en situación ${ }^{79}$. A su vez y en su opinión, los conflictos espontáneos que responden a momentos de exaltación o efervescencia colectiva deberían estudiarse con otro instrumental analítico.

Por último, Petar Hafner ${ }^{80}$ muestra preocupación por las ilustraciones sociales más o menos aceptadas por la comunidad científica que nos ofrecen los paradigmas sociológicos durante un cierto período de tiempo del desarrollo de la disciplina. Reclama, así pues, nuevos paradigmas que nos permitan entender los retos del futuro, aunque resulta notorio que las raíces funcionalistas y marxistas han permanecido como sustento profundo de las nuevas aportaciones. De acuerdo con Elster ${ }^{81}$, Hafner aboga por las teorías que son capaces de aplicar la pura descripción de generalizaciones empíricas a casos menores, a través de la interrelación entre problemas macro y micro, pudiendo así investigar todo segmento social.

76. J. Elster, "Marxismo, funcionalismo y teoría de juegos: alegato en favor del individualismo metodológico", Zona Abierta, 33, 1984, 21-62.

77. Cf. Supra, 7-8.

78. B. Tejerina Montaña, loc. cit., 47-63.

79. Ibid., 60.

80. P. Hafner, "Theories and paradigms in Sociology”, Facta Universitatis, series Philosophy and Sociology, vol. 1, 5, 1998, 455-464.

81. Cf. Supra, 11. 


\section{IV. Últimas aportaciones}

El siglo XXI no permanece ajeno a las nuevas reflexiones o a las revisiones críticas sobre las principales teorías del conflicto social. Especialmente interesantes resultan los trabajos de P. L. Lorenzo Cadarso ${ }^{82}$, por su aplicación práctica al análisis histórico ${ }^{83}$. Como historiador, reconoce que las aportaciones teóricas españolas al estudio de la conflictividad social o de los movimientos sociales han sido prácticamente nulas. Las renovaciones conceptuales foráneas han llegado siempre con retraso y su aplicación a la labor investigadora no ha dado los frutos deseados. El acusado presentismo ${ }^{84}$ de la teoría sociológica del conflicto limita su validez como instrumento de análisis histórico pero a su vez los estudiosos de los conflictos sociales históricos han ignorado casi por completo todas estas propuestas de carácter teórico. Por estos motivos, el autor riojano busca la aplicación de estos aparatos teóricos a períodos históricos preindustriales, evitando que el objeto o las evidencias factuales queden subyugadas por el método. Movido así por el rigor intelectual, contempla el eclecticismo como una necesidad impuesta por la práctica investigadora. Sin duda, la ampliación del repertorio de hechos sociales entendidos como formas de conflicto y la diversidad de disciplinas y enfoques que confluyen en su estudio, han terminado por introducir confusión incluso en la propia denominación del fenómeno ${ }^{85}$. Lorenzo Cadarso también establece una propuesta tipológica para los conflictos sociales ${ }^{86}$, centrando sus consideraciones sobre las causas de la confrontación en las percepciones subjetivas de la realidad experimentada. Interesado en los procesos de organización y movilización de los grupos enfrentados, indaga asimismo en cuestiones como la jerarquización interna, el aumento de la base social y el fortalecimiento del liderazgo como parte de un proceso progresivo configurado por fases consecutivas ${ }^{87}$. El estudio de los movimientos sociales, para él, exige un análisis sociológico mucho más detallado de lo que nos suelen ofrecer los trabajos de historia social ${ }^{88}$.

82. P. L. Lorenzo Cadarso, Fundamentos teóricos del conflicto social, Madrid, 2001; "Principales teorías sobre el conflicto social", Norba, Revista de Historia, 15, 2001, 237-254.

83. Vid. "Tipología de los conflictos sociales castellanos en los siglos XVI y XVII", Proserpina, Revista de la U.N.E.D, Extremadura, 10, 1993, 83-109; Los conflictos populares en Castilla en los siglos XVI y XVII, Madrid, 1996.

84. Cf. Supra, 1.

85. P. L. Lorenzo Cadarso, op. cit., n. 78, 12.

86. Ibid., 51 ss.

87. P. L. Lorenzo Cadarso, op. cit., n. 78, 128.

88. Cadarso recomienda un análisis pormenorizado de los niveles económicos de los diferentes sectores del grupo movilizado, rentas, relaciones con otros grupos, cualquier criterio significativo de ubicación social, necesidades y expectativas, recursos, sentimientos de identidad, formas ideológicas y culturales dominantes, objetivos y repertorios tácticos, escalada, resultados obtenidos, etc. Existen numerosos trabajos de historia social en España que han intentado establecer un recorrido cronológico a través de los conflictos sociales más destacados a lo largo del tiempo, si bien es cierto que la mayoría de éstos se caracterizan por su visible herencia marxista. Vid. J. M. Blázquez et al. Clases y conflictos sociales en la historia, Madrid, 1977; M. Pérez Ledesma, Estabilidad y conflicto social. España de los iberos al 14-D, Madrid, 1990. 
En 2002, un jurista argentino ${ }^{89}$ de reconocido prestigio en el campo de la filosofía del derecho, publicaba una obra de título especialmente sugerente para nuestro campo de estudio. Teoría de conflictos: hacia un nuevo paradigma es un trabajo muy completo que vincula el sistema jurídico con los conflictos y que cuenta con pretensiones teóricas generalistas. Interesado en consolidar un concepto universal de conflicto, que contemple un amplio universo de enfrentamientos, Entelman emprende una búsqueda de la esencia conflictual con el propósito de encontrar un modo de resolución polivalente. Consciente de la existencia de numerosos conflictos que no pueden ser resueltos por el derecho, porque no hay norma ni sanción al respecto, se muestra partidario de soluciones pacíficas, reglamentadas e institucionalizadas que se ven forzadas a excluir al derecho en tanto en cuanto éste es incapaz de desvincularse de la sanción y del monopolio coercitivo. A su juicio, la teoría de conflictos radica su quehacer en la descripción del enfrentamiento concreto, en el análisis de sus elementos y modo de ser, en la generación de los métodos a que da lugar la aplicación de sus conocimientos y en los desarrollos tecnológicos que realiza con auxilio multidisciplinar ${ }^{90}$. A pesar de todos los desarrollos teóricos que le preceden, el autor aprecia la teoría de conflictos como una actividad científica nueva que, como tal, carece de un sistema homogéneo de conceptos clasificatorios y de una nomenclatura autónoma suficiente ${ }^{91}$.

En 2004, desde el ámbito de la psicología social estadounidense, Dean Pruitt y Sung Hee Kim continúan la línea generalista marcada por Entelman en Social Conflict: Escalation, Stalemate and Settlement ${ }^{92}$. Con un interés similar en el análisis y en la resolución de los conflictos, estos autores consideran que toda confrontación, ya sea interpersonal, intergrupal, inter-organizacional o internacional, tiene una serie de elementos comunes que han de tomarse en consideración. Siguiendo los postulados de Simmel y Coser ${ }^{93}$, observan consecuencias tanto positivas como negativas en este tipo de pugnas definidas por la incompatibilidad de aspiraciones entre las partes ${ }^{94}$. En relación a los conceptos acuñados por la teoría de juegos ${ }^{95}$, las «actitudes y pensamientos de suma cero» incrementan la magnitud del conflicto por su rotunda negativa a la negociación.

Pruitt y Kim identifican y resumen las tácticas más empleadas por las autoridades fácticas durante el curso de un conflicto ${ }^{96}$, pero resulta más interesante aún el modelo dual que presentan sobre la percepción recíproca. Cuando la estimación de una parte con respecto a sí misma es alta y además tiene una percepción negativa del potencial del antagonista, el resultado es inevitablemente la contienda. Cuando una parte no confía en sus propias posi-

89. R. F. Entelman, Teoría de confictos: hacia un nuevo paradigma, Barcelona, 2002.

90. Ibid., 65.

91. Ibid., 75.

92. Esta obra no tiene aún traducción al castellano.

93. Cf. Supra, 2-3.

94. D. G. Pruitt, y S. H. Kim, Social Conflict: Escalation, Stalemate and Settlement, N. York, 2004, 10.

95. Cf. Supra, 7.

96. Hablamos de restar comunicación al grupo oponente, deshacerse de los líderes potenciales arrancando la cúspide de la pirámide y privando de organización al antagonista, o bien cooptarlos e integrarlos dentro del sistema. 
bilidades pero tampoco teme el potencial del oponente, el resultado será muy probablemente la inacción o la retirada. Cuando ambas partes confían en sus fuerzas y recursos pero asumen que el grupo hostil es igualmente poderoso, existe un alto grado de probabilidad de que se produzca una negociación. Por último, cuando no se confía en el potencial individual y se teme al adversario, se efectuará una concesión ${ }^{97}$. Tal y como anuncia el título de la obra, este trabajo expone un estudio secuencial sobre la escalada de los conflictos ${ }^{98}$, hasta que los lleva a un punto álgido o "callejón sin salida ${ }^{99}{ }^{»}$ que los reconduce hacia una solución ${ }^{100}$.

En los últimos diez años que separan el estudio mencionado del presente, tan sólo podemos reseñar algunos artículos ${ }^{101}$ bastante útiles como compendio, que nos ayudan a comprender la evolución sustancial que ha experimentado una materia tan amplia como la que nos compete. Del mismo modo, nos sirven para intuir la dirección tomada por los estudios más actuales, que delimitan la proyección de los trabajos venideros.

En uno de los artículos comentados, Roy Alfaro Vargas y Omar Cruz Rodríguez ${ }^{102}$ arremeten contra la deriva conservadora del dialogismo, característico de la ideología posmoderna, que instala al consenso en el epicentro de la teoría del conflicto social. Bajo su punto de vista, el consenso es, en última instancia, una expresión más del nihilismo que nos aqueja ${ }^{103}$.

\section{Consideraciones finales}

Expuesto el panorama secuencial de las principales aportaciones teóricas para la interpretación de los conflictos sociales, concluimos con una serie de reflexiones finales que podrían servir como epílogo del artículo.

Durante décadas, los trabajos históricos sobre la conflictividad social de cualquier etapa han sido monopolizados por la historia social. Comprendemos la parcelación y la división de la Ciencia histórica como un proceso lógico de la hiperespecialización académica, empero, haciendo uso de las palabras de L. Febvre ${ }^{104}$, pensamos que no hay historia económica y

97. Ibid., 41.

98. Ibid., 88 ss.

99. Ibid., 173 ss.

100. Ibid., 191 ss.

101. L. A. García, D. A. Muñoz, J. D. Gómez Quintero, "Aportes teóricos al concepto de conflicto social: una lectura desde las macro y microsociologías hasta los modelos integrados emergentes”, Virajes, Revista del Dpto. de Antropología de la Universidad de Caldas- Colombia, 8, 2006, 17-47; R. Alfaro Vargas, O. Cruz Rodríguez, "Teoría del conflicto social y posmodernidad”, Revista de Ciencias Sociales, 128-129, 2010, 63 70; M. Lube Guizardi, "Conflicto, equilibrio y cambio social en la obra de Max Gluckman”, Papeles del CEIC, International Journal on Collective identity Research, 2, 2012, 1-47.

102. R. Alfaro Vargas, O. Cruz Rodríguez, “Teoría del conflicto social y posmodernidad”, Revista de Ciencias Sociales, 128-129, 2010, 63-70.

103. Ibid., 69.

104. L. Febvre, Combates por la historia, Barcelona, 1970, 39. 
social, hay historia sin más, en su unidad. La importancia de la parte no debería dificultar la visión del conjunto.

Asimismo, la investigación sobre los diferentes episodios de conflictividad social en la historia ha contado con una ingente cantidad de estudios concretos que frecuentemente se han servido de las diversas teorías sociológicas del conflicto para corroborar metodologías fuertemente politizadas ${ }^{105}$, en contra de las bases consustanciales de la objetividad científica.

Por otro lado, las perspectivas excesivamente abstractas, incluso a veces nomotéticas y estáticas de la teoría sociológica no han encajado con el profundo particularismo que envuelve a los complejos procesos de conflictividad social histórica. Tampoco la sociología histórica ${ }^{106}$, más interesada en las construcciones políticas de larga duración, ha satisfecho las necesidades propias de nuestra investigación.

Por tanto, planteamos la adaptación particular de los elementos analíticos más apropiados de los diversos paradigmas sociológicos del conflicto como herramienta de posible utilidad para la investigación histórica concreta. Contrarios al dogmatismo metodológico y partidarios del eclecticismo pragmático, consideramos a su vez que el radicalismo empírico opuesto al uso de cualquier tipo de perspectiva teórica está dando la espalda a una fuente importante de análisis interpretativo.

105. E. g, P. Blackledge, Reflections on the Marxist Theory of History, Manchester/N. York, 2006. Esta alusión no establece ningún cuestionamiento sobre los aspectos positivos de las muchas aportaciones de la historia marxista británica. Vid. E. Hobsbawm, E. P. Thompson, P. Anderson, etc.

106. Hacemos referencia a autores como S. Eisenstadt, B. Moore, C. Tilly, T. Skocpol, M. Mann, I. Wallerstein. 
